\title{
La explicación en la enseñanza de la Filosofía: la búsqueda de un devenir menor ${ }^{1}$
}

Laura M. Galazzí

professora de Filosofia (Ensino Médio e Superior) pela Universidad de Buenos Aires

\section{RESUMO}

Nas aulas de Filosofia a explicaşão tem uma primazia que é importante rever, principalmente quando somos confrontados com a crítica dessa prática feita por Jacques Rancière em $O$ mestre ignorante. Nesse trabalho a explicação é conceituada como a cristalização de uma relação de desigualdade, que veda a possibilidade de emancipação intelectual. Propomos a revisão do conceito de explicação utilizando o conceito de "literatura menor" cunhado por Deleuze e Guattari; usamos, a propósito, algumas contribuições de Basil Bernstein que parecem complementar e esclarecer a questão d'O mestre ignorante.

Palavras-chave: explicação; ensino de Filosofia; literatura menor.

\section{RESUMEN}

En la clase de Filosofía la explicación tiene una primacía que resulta importante revisar, sobre todo cuando nos encontramos con la crítica a la que se la somete en El maestro ignorante de Jacques Rancière. En esta obra se conceptualiza a la explicación como la cristalización de una relación de desigualdad, que obtura la posibilidad de una emancipación intelectual. Se propondrá la revisión de este concepto, utilizando para ello el concepto de "literatura menor" acuñado por Deleuze y Guattari; se utilizarán al pelo algunos aportes de Basil Bernstein que parecen poder complementar y clarificar el planteo del Maestro ignorante.

Palabras clave: explicación, enseñanza de la Filosofía, literatura menor.

\footnotetext{
${ }^{1}$ Una primera versión de este artículo fue publicada en CERLETTI, A.; COULÓ, A. (orgs.) La enseñanza de la filosofía: teoría y experiencias, OPFyL, Buenos Aires, 2009. La autora agradece a los organizadores la autorización para utilizar partes del artículo original en esta nueva versión.

${ }^{2}$ Profesora Titular de la cátedra "Filosofía" en la carrera de Artes Audiovisuales del Instituto Universitario Nacional de Artes (IUNA) y ayudante de primera categoría en la cátedra "Didáctica especial y prácticas de la enseñanza en filosofía" de la carrera de Filosofía (UBA).
}

Filosofia e Educação - ISSN 1984-9605 - v. 4, no 1, abril-setembro de 2012 
De ahí que haya caído en algo, por una vez, característico de una niña de mi edad, como es la identificación con la maestra. Todas las niñas pasan por esa etapa, y por esa actividad casi febril de dar clase a sus muñecas o a los niños imaginarios que las habitan. Qué ridículo que quien no sabe se ponga a enseñar con tanto ahínco. Pero qué ridículo sublime. Qué catecismos de dogma didáctico salvaje están esperando ahí al observador sagaz. Qué moral de acción (AIRA, 1993, p. 15).

Cotidianamente servimos a fuerzas inconmensurables como el dormir. Lo que hacemos y pensamos se encuentra lleno del ser del padre y de los antepasados. Nos esclaviza sin descanso un simbolismo no comprendido. A veces, al despertar, logramos recordar un sueño (BENJAMIN, 19121916, p. 69).

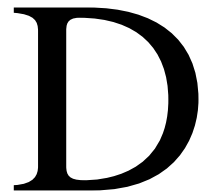

os citas en el comienzo que demarcan un plano: la primera con la constatación de una pulsión irrefrenable en nosotros los docentes - y cuánto más los docentes de filosofía - por explicar, por enseñar con ahínco, como la niña a las muñecas. No importa qué, bien lo dice Aira, aún podemos no saber nada. Ese placer de explicar aún lo que no se sabe es un "catecismo de dogma didáctico salvaje", una "moral de acción" sobre los que resulta interesante y necesario posar la mirada, como ya ha hecho magistralmente Rancière en El maestro ignorante, utilizando para ello la experiencia de Jacotot. Se tratará, entonces, de pensar la explicación en el ámbito de la enseñanza de la filosofía, a partir del problema que Rancière deja planteado y que no podemos evitar enfrentar. Para revisar y resignificar esta cuestión utilizaremos el concepto de enmarcamiento acuñado por Basil Bernstein.

Luego, la cita de Benjamin, que de una manera muy bella nos dice que nuestra vida puede ser entendida como un largo dormir, en el que fuerzas inexplicables para nosotros, que se transmiten de generación en

Filosofia e Educação - ISSN 1984-9605 - v. 4, no 1, abril-setembro de 2012 
generación y trascienden en mucho nuestro ser individual, nos sujetan a maneras de ser, hacer y pensar. Son nuestros antepasados los que generalmente hablan en nosotros, las tradiciones y los automatismos de la cultura los que nos conducen a la acción. Sin embargo, también dice Benjamin que algunas veces podemos despertar y recordar un sueño. Parece posible, aunque dificultoso y complejo, revisar esas fuerzas inconmensurables y pensar a través de ellas para que algo nuevo acontezca. En este sentido se propondrá pensar de modo alternativo la explicación filosófica a través del concepto de literatura menor creado por Deleuze y Guattari. En este esfuerzo le debo mucho a Sílvio Gallo que utiliza este concepto para pensar la relación entre filosofía y educación en su obra Deleuze \& a Educação (2003), y que guía con sus consideraciones algunas de ideas que propondremos en este trabajo.

\section{La explicación en filosofía}

La enseñanza de la filosofía tiene una relación muy especial con la explicación quizá debida a su vínculo estrecho con los textos. En efecto, si bien otras disciplinas, como los estudios literarios por ejemplo, se concentran también en análisis de textos, podríamos decir que ellas establecen una relación distinta con los mismos, dando lugar a diversas interpretaciones y solicitando necesariamente la conservación de un fondo de ambigüedad en la lectura. La filosofía en cambio - y sobre todo la filosofía escolarizada tanto en el nivel medio como superior - suele precipitarse a una tarea de interpretación que busca dar con la lectura "correcta", por no decir "verdadera", del texto filosófico. El foco de atención está puesto en las ideas de los autores, más que en la forma de su expresión, y es en este sentido que el filósofo siempre está a la búsqueda de traspasar las dificultades interpretativas que el texto propone para dar con

Filosofia e Educação - ISSN 1984-9605 - v. 4, no 1, abril-setembro de 2012 
una lectura que capte "mejor" los conceptos filosóficos a los que la obra intenta dar lugar.

Por otra parte, a diferencia de las ciencias exclusivamente teóricas que también se construyen alrededor de textos, no existe una filosofía paradigmática y normal que pueda borrar la relación con la tradición y restringir el estudio a los manuales más "actualizados" que recogen los avances en el campo. La filosofía a lo largo de la historia se sigue relacionando con todas las fuentes de la tradición, y en función de ello establece categorizaciones, cánones, herencias que requieren para el filósofo ser explicados, abordados, explicitados.

Por otra parte, el lenguaje filosófico gusta de la aclaración terminológica, la distinción sutil, la formulación compleja de las ideas, la argumentación y contra-argumentación exhaustiva, el lenguaje diversificado cercano a la poesía en algunos casos, cercano a las ciencias más duras en otros; elementos textuales que invitan al profesor de filosofía a adentrarse a largas disquisiciones sobre la materia. La pequeña maestra de muñecas que llevamos dentro se halla, seguramente, ampliamente agradecida con la disciplina que hemos elegido para enseñar.

Quizá por todo eso El maestro ignorante es un libro que puede resultarnos verdaderamente molesto en algunos de sus pasajes. Por ejemplo, aquel que afirma: "El niño que balbucea bajo la amenaza de los golpes obedece a la férula, y ya está: aplicará su inteligencia para otra cosa. Pero el pequeño explicado, él, empleará su inteligencia en ese trabajo de duelo: comprender, es decir, comprender que no comprende si no se le explica" (RANCIÈRE, 1987, p. 19) ¿Cómo es eso de que explicar es una estrategia para embrutecer? ¿Qué queda de la filosofía si no es explicada? ¿Es posible que un novato en filosofía - y siempre somos novatos por distintas razones - se acerque al texto sin ninguna mediación y entienda algo? ¿No es la explicación una herramienta fundamental para la enseñanza de la filosofía?

Filosofia e Educação - ISSN 1984-9605 - v. 4, no 1, abril-setembro de 2012 
Es claro que estas preguntas surgen de un malentendido: El maestro ignorante no es un manual de pedagogía. En realidad, resulta un problema el género de la obra, que no podré tratar aquí. Pasaré rápido la cuestión adoptando una posición (provisoria, en vistas de avanzar en este trabajo), que se concentra en la lectura del subtítulo, "cinco lecciones sobre la emancipación intelectual”, y consideraré que su eje principal es la política, y más específicamente aún, una fuerte crítica a la idea de una vanguardia iluminada que "conoce" una verdad y la revela a otros.

En este sentido, la crítica es feroz. Nadie puede emancipar a otros, nadie puede iluminar y esclarecer, y todo aquel que lo intente está siempre él mismo más embrutecido que aquel a quien pretende liberar. De todos modos, ocurre en nuestro caso que cuando leemos El maestro ignorante no podemos escindirnos y desapropiarnos. Es un texto que nos incluye en su interpelación política dirigida a todos sin distinciones, y también nos es atinente en nuestro rol docente, ya que somos de algún modo el paradigma, la metáfora, el caso testigo de la institución de la desigualdad entre las personas.

Terrible provocación que nos enfrenta a encrucijadas, nos conduce a pensar nuevamente todo eso que llamamos educación, hace que vivenciemos un conflicto entre lo que hacemos y lo que decimos, lo que pensamos y lo que actuamos. El problema que genera es, según creo, la mejor potencia del Maestro ignorante. Su contratara: esta intensidad en la denuncia y esta efectividad en la problematización, impide que sea un texto donde ir a buscar respuestas y mucho menos una nueva forma de educar. Y nosotros necesitamos realizar esa búsqueda, en tanto elegimos hacer de la tarea de enseñar filosofía una parte fundamental de nuestra vida.

Así, intentaré valerme de otras fuentes para pensar en la incomodidad del automatismo. En este caso, para reflexionar sobre la explicación: en el Maestro ignorante se pretende sacar a la luz la estructura

Filosofia e Educação - ISSN 1984-9605 - v. 4, no 1, abril-setembro de 2012 
básica de la explicación escolarizada. En principio, se evidencia que toda explicación supone una regresión al infinito: el libro está escrito para ser comprendido, por tanto la explicación del maestro lo es de una explicación, y en caso de no comprenderse, habría que recurrir a una explicación de la explicación, etc. Sin embargo, no es este el argumento más convincente: en efecto, la hermenéutica había señalado ya que el proceso de interpretación es circular y no por ello carece de sentido. Explicar una explicación, si no es concebido como una mera repetición, puede constituir una oportunidad para apropiarse del sentido y reconfigurarlo para concebir nuevas ideas.

Resulta entonces importante señalar que recién cuando la explicación es contextualizada en una estructura institucional, como la escolar, se puede evidenciar su carácter de relación de poder: el maestro explica porque se constituye en una autoridad guardiana del libro y puede articular el arte de la distancia (RANCIÈRE, 1987, p. 19). Afirma Rancière (1987, p. 19) que el explicador es, a la vez, "quien plantea y da por abolida la distancia, quien la despliega y la reabsorbe en el seno de su palabra". El explicador escolar rodea a la explicación de varios dispositivos, entre ellos podríamos pensar que el examen es el principal, y es con su inclusión que se culmina la regresión al infinito, se concluye el círculo hermenéutico y se da lugar a la certificación exterior de un saber.

Lo que se instaura, entonces, es principalmente una legitimidad cultural: el proceso de conocimiento no puede ser una experiencia personal guiada por el ensayo y el error (como lo fue hasta el comienzo de la escolarización del niño), sino que tiene una forma "correcta" en la que se precisa de escalafones intelectuales para que unos puedan explicar a otros, que al final del proceso logran entender. La asimetría constituye el ingreso a la cultura. Para cortar esta cadena de instauración de desigualdades es necesario comenzar por la aplicación de un axioma: "todos somos iguales". La instauración del mismo es condición de posibilidad para la 
emancipación. De otro modo, los contenidos supuestamente emancipadores son una oposición irrisoria para contrarrestar la lógica embrutecedora del proceso de explicación. Hasta aquí Rancière.

Ya que como se afirmó la explicación resulta embrutecedora en tanto $y$ en cuanto se halle enmarcada en un contexto institucional, resulta necesario revisar en profundidad las características propias de la explicación institucionalizada. Para ello puede resultar útil el concepto de enmarcamiento que propone Basil Bernstein. Este concepto es utilizado por el autor para describir la lógica interna de la comunicación pedagógica considerada legítima. Es definido como el principio que:

Regula las reglas de realización para la producción del discurso [...] Regula las relaciones dentro de un contexto, se refiere a las relaciones entre los que transmiten y los que adquieren el conocimiento, relaciones en las que los adquirientes hacen suyos los principios de la comunicación legítima” (BERNSTEIN, 1996, p. 44).

El enmarcamiento dispone las normas de interacción pedagógica que permiten vehiculizar un mensaje, a la vez que instituye y legitima una forma específica de comunicación. Se trata, como afirma el autor de "quien controla algo". Algunos ejemplos de lo que se controla son para Bernstein (1996, p. 44): “La selección de la comunicación; su secuenciación (qué es lo que va antes y qué es lo que va después); su ritmo (el grado previsto de adquisición), los criterios y el control de la base social que hace posible esta transmisión".

Como podemos observar, se trata de un concepto estructural que intenta dar cuenta de los contextos en los que los individuos se insertan. Los elementos señalados (una cierta idea del ritmo, la secuenciación, la selección de los contenidos legítimos, la certificación social) pueden ayudar a precisar aquello que genéricamente podemos llamar "explicación”. Ella se

Filosofia e Educação - ISSN 1984-9605 - v. 4, no 1, abril-setembro de 2012 
halla enmarcada porque se inserta en una estructura en la que se amoldan las intervenciones y se controla lo que es legítimo hacer y lo que no, lo que es pensable y lo que resulta impensable, a la vez que un quien que detenta la autoridad legítima en cada caso. Pensar desde el contexto del enmarcamiento corre el eje de la discusión ya que visibiliza que el control no va en una sola dirección (del docente al alumno), sino que se expande en todas las direcciones porque involucra a los individuos antes de participar de sus roles, los subjetiviza. Este corrimiento que podríamos llamar "estructuralista" quizá no pueda admitirse en el contexto de la obra de Rancière, sin embargo, considero que da cuenta de una forma más cabal de que la explicación en su aparición fáctica es una práctica emergente de un contexto estructural más amplio, que justamente la enmarca. Los profesores de filosofía estamos articulados por los ritmos, los criterios, la secuenciación y la selección que la explicación filosófica ha adquirido en la tradición canónica. Nosotros nos formamos en ella, la encarnamos luego, reproducimos y vivenciamos en nosotros esos criterios. Para utilizar una imagen, podríamos pensar que la explicación filosófica es como una melodía, que nos ha atrapado desde nuestra formación y que no podemos dejar de repetir en ninguna de las instancias que consideramos filosóficas: en la enseñanza, en las comunicaciones en congresos, en los artículos y escritos, incluso en nuestras charlas cotidianas con colegas. Como siempre, con los automatismos del lenguaje, como gusta llamarlos a Nietzsche, sólo se puede efectuar un juego en los límites: no se puede pensar sin el lenguaje heredado, a la vez que éste nos constriñe y nos empuja a concebir sólo lo que en su estructura es concebible. El desafío pasa a ser cómo desarticular el marco para que sea otra cosa, y eso no es tan simple como afirmar que hay que dejar de explicar. Un camino interesante para afrontarlo lo proponen, según creo, Deleuze y Guattari cuando piensan a Kafka a través del concepto de "Literatura menor"

Filosofia e Educação - ISSN 1984-9605 - v. 4, no 1, abril-setembro de 2012 


\section{Una filosofía menor}

La explicación en la enseñanza filosófica, entonces, es un problema en tanto se impone como una estructura que nos determina. Adormecernos en esa melodía, estructurarnos en ese marco, embrutece y nos embrutece en tanto impone una acción que sólo puede ser pensada desde la perspectiva de la repetición: transmitimos insistentemente una cultura hegemónica, nos encuadramos sin excepción en un contexto que nos limita y lo hacemos aún cuando creemos estar más lejanos de ello o estar haciendo otra cosa. Frente a esta perspectiva, sería muy simplista pensar que la solución es dejar de explicar la filosofía cuando la enseñamos ya que el docente, el texto y el alumno están enmarcados. En primer lugar el texto: aún acercándolo sin palabras mediante, esperando que se establezca una comunicación supuestamente "prístina" y originaria, impone efectos de autoridad, se propone a sí mismo como una explicación, es hijo de una tradición, establece una distancia y jerarquía respecto de sus destinatarios (¿o alguien se ha sustraído al efecto de disminución de la inteligencia que produce el primer encuentro con Kant, con Hegel? ¿O acaso nunca hemos sentido que esos arcanos lingüísticos eran indescifrables y se hallaban en un cielo inaccesible para nosotros?) En segundo lugar quien lee sin explicación mediante ya posee una idea de cómo leer en el contexto escolar y tiene una serie de pautas esteriotipadas de cómo ser "alumno". Buscar las "ideas principales", "sintetizar", "subrayar", suelen ser formas de lectura escolarizada que constituyen ya una forma de explicación, anterior a toda intervención de nuestra parte. En algunos casos, esas formas de lectura escolares estandarizadas constituyen un obstáculo importante para el trabajo con fuentes filosóficas. Por último, nosotros con nuestro silencio, con nuestras apelaciones a un supuesto poder originario de la voluntad del otro, podemos (y solemos hacerlo) adoptar un halo misterioso, producir un efecto

Filosofia e Educação - ISSN 1984-9605 - v. 4, no 1, abril-setembro de 2012 
de autoridad que puede resultar tanto o más embrutecedor que nuestros intentos por explicar los conceptos.

Resulta claro que estas consideraciones merecen un trabajo más pormenorizado de argumentación. Me bastaría que sugieran que es demasiado simplista suponer solucionado el problema de la asimetría embrutecedora con solo dejar de explicar. La paradoja en la que nos hallamos es más compleja, similar a la que constata Kafka respecto a su lugar como judío checo escribiendo en alemán: “imposibilidad de no escribir, imposibilidad de escribir en alemán, imposibilidad de escribir de cualquier otra manera". Traducida, la nuestra sería "imposibilidad de no explicar" en tanto decidimos que el problema del embrutecimiento filosófico no se soluciona con dejar de hacerlo, "imposibilidad de explicar en la lengua magistral de la filosofía" luego lo trabajaremos, pero en principio, simplemente porque ya no somos inocentes e intuimos el embrutecimento al que sometemos al otro, por último, "imposibilidad de explicar de cualquier otra manera", en tanto todavía no inventamos alternativas y andamos a ciegas.

Esta paradoja, sin embargo, lejos de ser paralizante, es un motor para la aparición de otro tipo de lenguaje en la obra de Kafka, al menos tal como ésta es leída por Deleuze y Guattari. Aquí intentaré resignificar esa lectura para pensar a la explicación en la enseñanza de la filosofía. Para ello, trataré de seguir la exposición de los autores sobre el concepto de "literatura menor" estableciendo las extrapolaciones que pretendemos hacer para el ámbito de la enseñanza de la filosofía.

En principio: ¿Qué es una literatura menor? Es "la literatura que una minoría hace dentro de una lengua mayor", su primera característica es que “el idioma se ve afectado por un fuerte coeficiente de desterritorialización”. Es decir, hay un idioma hegemónico, poderoso, el de la llamada "literatura mayor", ese mismo lenguaje es utilizado por una minoría desacreditada,

Filosofia e Educação - ISSN 1984-9605 - v. 4, no 1, abril-setembro de 2012 
menor, y por ello necesariamente apropiado, reterritorializado. Pensaba que esta primera característica podría aplicarse doblemente a nuestro espacio de la enseñanza de la filosofía. En primer lugar, porque todos nosotros, docentes e investigadores latinoamericanos, estamos en un lugar periférico respecto de la filosofía hegemónica. Siempre intentando formar parte de discusiones cuyo centro se encuentra en otros lugares geográficos y simbólicos, construimos nuestras ideas como deudoras de una "Filosofía mayor". No tenemos autores que pertenezcan al canon de la gran filosofía, ni prosapia filosófica que enarbolar. Somos parte de una filosofía del subdesarrollo.

En segundo lugar, la enseñanza de la filosofía suele ser considerada, frente a la producción filosófica que surge de la investigación por ejemplo, un lenguaje menor, un género degradado que no alcanza el estatus filosófico y por ello tiene que abordar todo el tiempo su propia legitimación. En tanto docentes, somos el último eslabón del subdesarrollo, el género más degradado de lo real. Doblemente, entonces, pertenecemos a una minoría (aunque no numérica) dentro de un lenguaje mayor. Claro que este es un gran obstáculo para una filosofía que aspira a volverse mayor, pero una oportunidad si uno pretende hacer otra cosa. Por ejemplo, una filosofía menor.

En efecto, volviendo a la consideración de las literaturas menores, ellas tienen dos características más que las hacen atractivas a nuestros ojos: una es que "todo en ellas es político", la otra que "todos sus enunciados adquieren un valor colectivo". Estas dos características se hallan relacionadas, porque su sustento está justamente en el espacio marginal del que surgen estas literaturas. El espacio minoritario, poco individualizado e indiferenciado en el plano social, que desdibuja el rostro personal del excluido, hace que aún las más triviales circunstancias que en ellas se describen tengan un significado político inmediato, así como no hay en ellas

Filosofia e Educação - ISSN 1984-9605 - v. 4, no 1, abril-setembro de 2012 
genio o "gran maestro" que pueda ponerse como figura detrás de los enunciados. Nunca son personales y lo que se dice es anónimo y para todos ${ }^{3}$.

Nosotros vivenciamos estas características en la doble degradación del aula: en primer lugar, tenemos que ser muy poco perceptivos al entorno para no notar que cuando queremos anunciar con gran erudición la filosofía mayor en el aula, algo incómodo ocurre. Cuanto más marginal es nuestro lugar en el sistema educativo, más evidente se hace que las cuestiones abstractas y venerables de la filosofía están desoyendo esa situación, y niegan - con la fuerza con que se niega un trauma - el vínculo político con la situación singular del aula. La contracara de esta negación es que resulta de ella una revelación que está allí siempre disponible, a la espera de ser explorada: el conflicto entre el lenguaje hegemónico de la filosofía y las formas de experiencia que conviven en el aula es, por sí mismo, un conflicto político entre tipos de lenguaje y tipos de pensamiento que merece ser abordado. Cuanto más desoímos el conflicto y actuamos de un modo pretendidamente neutral, más nos involucramos políticamente en el sostenimiento del orden hegemónico. Aceptar, en cambio, esta afloración irreprimible de lo político en el aula a través del conflicto de los lenguajes, intentar construir una filosofía menor que reniegue de los lazos eruditos con el pasado sin renegar con ello de la filosofía, que subvierta su lenguaje descaradamente, constituye un gesto político de confrontación con la hegemonía. Debemos agregar que esto puede hacerse con cualquier contenido filosófico, quizá aún más con los contenidos de la metafísica y la ontología que con los de la filosofía política o la ética. Esto, porque toda la filosofía se vuelve promesa de cambio político y adquiere el valor de lo colectivo cuando se perturba el poder del lenguaje mayor y se lo utiliza para otra cosa.

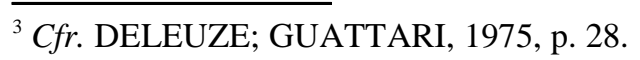

Filosofia e Educação - ISSN 1984-9605 - v. 4, no 1, abril-setembro de 2012 
Se trata de mutaciones del lenguaje: en apariencia usamos las mismas palabras, trabajamos sobre los mismos conceptos, revisamos los mismos autores. Pero solo en apariencia: en ese hacer no estamos intentando imponer un efecto de autoridad a través de ellos, no proponemos a los alumnos que ese es el lenguaje inmutable de la cultura que deberían alcanzar. Por el contrario, tomamos los conceptos, las ideas y las palabras como una oportunidad, una invitación a trastocarlos, mutarlos, desfigurarlos irremediablemente para forzarnos a pensar distinto, para obligarnos a darle lugar a lo impensado. En la transmutación, es evidente que la explicación deja de ser clase magistral. También deja de ser principio de entendimiento y lugar central del sentido. El profesor puede ser quien dice las palabras, pero si su intento es el de realizar una filosofía menor de lo que se trata es de hablar para apropiarse de las palabras, el profesor al mismo tiempo que los alumnos. Paladearlas, aplicarlas a cosas nuevas, probarlas en circunstancias diferentes, de inventar un nuevo lenguaje a partir del lenguaje mayor de la filosofía. Y ese invento se vuelve irremediablemente colectivo en el aula. Esta alquimia que transmuta el valor del lenguaje tiene una potencialidad revolucionaria. Deleuze y Guattari trabajan sobre este proceso en Qué es filosofía, describiéndolo como sigue:

Artaud decía: escribir para los analfabetos, hablar para los afásicos, pensar para los acéfalos. ¿pero qué significa "para"? No es "dirigido a...", ni siquiera "en lugar de...". Es "ante”. Se trata de una cuestión de devenir. El pensador no es acéfalo, afásico o analfabeto, pero lo deviene. Deviene indio, no acaba de devenirlo, tal vez "para que" el indio que es indio devenga él mismo algo más y se libere de su agonía. Se piensa y se escribe para los mismísimos animales (DELEUZE; GUATTARI, 1991, p. 121122).

Filosofia e Educação - ISSN 1984-9605 - v. 4, no 1, abril-setembro de 2012 
A las imágenes propuestas por los autores (devenir animal, indio, afásico, acéfalo), podríamos agregarles las que surgen de cualquier aula de nuestras escuelas: devenir boliviano, paraguayo, villero, chorro, homosexual, mujer. Este devenir constituye una elección muy importante que el profesor de filosofía: creímos que se trataba de devenir Sócrates, Hegel o Kant, y con ello volvernos sabios, pero descubrimos que ese es el marco en el que nos enmarcaron, el poder al que nos sometimos sumisamente.

Digámoslo de otra manera: si al principio afirmábamos que una de las implicancias políticas más importantes de la crítica de El maestro ignorante a la explicación era su recusación a la posibilidad de una vanguardia iluminada, podemos encontrar una idea similar en la obra de Deleuze. En efecto, una de las principales afirmaciones políticas de Kafka a la que Deleuze vuelve una y otra vez en distintas momentos, es la idea de que "el pueblo falta". Esto es, si el pensamiento político clásico pensaba que el pueblo estaba allí y que la función de la militancia política era desalinearlo e iluminarlo para que se convierta en agente de la revolución, es necesario pensar que el pueblo falta si se quiere pensar otra política. A diferencia del efecto paralizante que provoca a veces la crítica de Rancière, que el pueblo falta quiere decir que nadie tiene una verdad que pueda iluminar al pueblo (ni el artista, ni el intelectual), pero que la política sería un intento por inventar ese pueblo, por devenir agente de una revolución, por ser pueblo más que por educar al pueblo. Como comenzamos diciendo en este trabajo, todos estamos bajo el influjo de un sueño, todos somos colonizadores y colonizados a la vez. Es necesario entonces emprender la tarea de devenir. Cito a Deleuze:

El devenir siempre es doble, y este doble devenir es lo que constituye un pueblo venidero y la tierra nueva. La filosofía tiene que devenir no filosofía, para que la no filosofía devenga la tierra y el pueblo de la

Filosofia e Educação - ISSN 1984-9605 - v. 4, no 1, abril-setembro de 2012 
filosofía. [...] El pueblo es interior al pensador porque es un "devenirpueblo" de igual modo que el pensador es interior al pueblo, en tanto que devenir no menos limitado. El artista o el filósofo son del todo incapaces de crear un pueblo, sólo pueden llamarlo con todas sus fuerzas [...]

Devenir forastero respecto a uno mismo, y a su propia lengua y nación, ¿no es acaso lo propio del filósofo y de la filosofía? (DELEUZE; GUATTARI, 1991, p. 122-123).

Una nueva imagen: el devenir forastero sería la condición para una filosofía menor, la que se siente extraña en la lengua de la filosofía mayor pero, en vez de afanarse por hablarla cada vez con más refinamiento deseosa de volverse una filosofía de Estado o una lengua oficial, la habla subvirtiéndola, encontrando en ella una oportunidad para devenir otra cosa. Deleuze y Guattari usan muchas expresiones más que nos sirven para pensar este intento por devenir minoritarios: ser extranjeros en nuestra propia lengua, escribir como un perro escarba en su hoyo, como una rata hace su madriguera, encontrar el propio punto de subdesarrollo, la propia jerga, el propio tercer mundo, el propio desierto ${ }^{4}$, volvernos el nómada, el inmigrante, el gitano ${ }^{5}$, odiar toda filosofía de amos y maestros ${ }^{6}$, emitir graznidos dolorosos como Gregorio en La metamorfosis.

Los graznidos dolorosos son bien representativos: un buen índice de la filosofía menor es la incomodidad. Una incomodidad placentera, porque es la que surge de la búsqueda, del inconformismo. Nunca sabremos en definitiva si proferimos palabras con sentido o sonidos animales. Podríamos pensar que lo contrario de la incomodidad es el gesto autocomplaciente del sabio, que mira al mundo con desdén y se cree poseedor de la verdad. Nosotros en cambio, estamos incómodos cuando hablamos en el aula, cuando conversamos e inventamos con nuestros alumnos, nos preguntamos

${ }^{4}$ Cfr. Ibidem, p. 30.

${ }^{5}$ Cfr. Ibidem, p. 31.

${ }^{6}$ Cfr. Ibidem, p. 43.

Filosofia e Educação - ISSN 1984-9605 - v. 4, no 1, abril-setembro de 2012 
si lo que estamos haciendo será o no filosofía, tendrá o no un sentido futuro, clamará o no por un pueblo, por otro lenguaje, por otro porvenir. Si damos clase explicando febrilmente como la niña de Aira a las muñecas, si sentimos ese placer egoísta enorme que siempre significa mostrarle a otros que están muy lejos de penetrar en los arcanos de un lenguaje inaccesible, entonces seguramente algo anda mal. Intentar devenir otra cosa de lo que somos invitando a otros cada vez a hacerlo, probablemente no nos traerá la gloria de los sabios, ni la admiración boba de los que prefieren ser embrutecidos. Sí, evitará que nos dejemos arrastrar por la pulsión pedagógica salvaje, sí nos ayudará en nuestro intento de recordar un sueño, sólo eso.

\section{Bibliografía citada}

AIRA, C. (1993): Cómo me bice monja, Rosario, Beatriz Viterbo Editorial.

BENJAMIN, W. (1912-16): "Metafísica de la juventud" en Ensayos VII, Madrid, Editora Nacional, 2002, p. 69-75.

BERNSTEIN, B. (1996): Pedagogía, control simbólico e identidad, Madrid, Morata, 1998.

DELEUZE, G.; GUATTARI, F. (1975): Kafka. Para una literatura menor, Madrid, Editora Nacional, 2002.

(1991): ¿Qué es la filosofía?, Madrid, Editora Nacional, 2002.

GALLO, S. (2003): Deleure \& a Educaşão, Belo Horizonte, Autêntica.

RANCIÈRE, J. (1987): El maestro ignorante. Cinco lecciones de emancipación intelectual, Buenos Aires, Libros del Zorzal, 2007.

Filosofia e Educação - ISSN 1984-9605 - v. 4, no 1, abril-setembro de 2012 